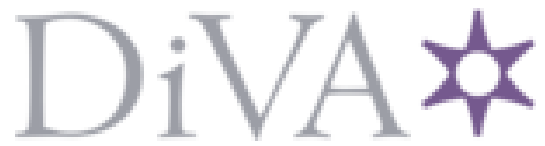

http://www.diva-portal.org

Postprint

This is the accepted version of a paper presented at The Fifth IFIP Conference on Sustainable Internet and ICT for Sustainability.

Citation for the original published paper:

Björn, H., Lundström, A., Westlund, M., Markström, E. (2017)

The Energy Piggy Bank - A Serious Game for Energy Conservation.

In: The Fifth IFIP Conference on Sustainable Internet and ICT for Sustainability,

Funchal, Portugal, December 6-7, 2017

N.B. When citing this work, cite the original published paper.

Permanent link to this version:

http://urn.kb.se/resolve?urn=urn:nbn:se:kth:diva-219781 


\section{The Energy Piggy Bank - A Serious Game for Energy Conservation}

\author{
Björn Hedin \\ Media Technology and \\ Interaction Design \\ KTH Royal Institute of \\ Technology \\ Stockholm, Sweden \\ bjornh@kth.se
}

\author{
Anton Lundström \\ Media Technology and \\ Interaction Design \\ KTH Royal Institute of \\ Technology \\ Stockholm, Sweden \\ bjornh@kth.se
}

\author{
Magnus Westlund \\ Media Technology and \\ Interaction Design \\ KTH Royal Institute of \\ Technology \\ Stockholm, Sweden \\ mwestlu@kth.se
}

\author{
Erik Markström \\ Media Technology and \\ Interaction Design \\ KTH Royal Institute of \\ Technology \\ Stockholm, Sweden \\ erimar@kth.se
}

\begin{abstract}
Serious games have attracted much attention recently and are used to in an engaging way support for example education and behavior change. In this paper, we present a serious game designed for helping people learn about their own energy consumption and to support behavior change towards more sustainable energy habits. We have designed the game for all the four Bartle Player Types, a taxonomy used to identify different motivations for playing games. Engagement of the participants has been evaluated using the Intrinsic Motivation Inventory, and we have measured self-assessed future behavior change. We found a statistically significant positive correlation between self-assessed future behavior change and perceived value/usefulness of the application independent of player type. Our study indicates the player type "Achievers" might perform better using this type of application and find it more enjoyable, but that it can be useful for learning energy conserving behavior independent of player type.
\end{abstract}

Keywords - Serious games, gamification, energy conservation, energy efficiency, behavior change, Bartle Player Type

\section{INTRODUCTION}

Domestic energy consumption is a major contributor to the emission of greenhouse gases and, consequently, global warming, and in the EU households account for about $25 \%$ of total energy consumption [1].

Broadly speaking energy conservation and energy efficiency in households can be achieved in two ways: We can make our homes more energy efficient by for example installing better insulation, switching to more efficient heating sources, or when buying new appliances, choosing the most energy efficient alternative. We can also make behavioral changes, adjusting the way we use energy in our homes and how we operate appliances. Although one-time changes tend to be more effective [2] behavioral support is still needed in order to minimize the risk of rebound effects [3], where final energy consumption can be described as an interplay between onetime adjustments and changes in behavior [4][2]. One way ICT could support a transition toward sustainable energy consumption patterns is by enabling such behavior change [5]. ICT can and has (for a fairly long time) been used for persuasion [6], eco-feedback [7], quantified self [8], and can be useful in increasing awareness and knowledge on how everyday choices affects the environment [9] and let the user adjust behavior accordingly.

In recent years gamification and serious games approaches have become increasingly popular when designing ICT-driven behavior change interventions. The former is defined as "the use of game-elements in non-gaming contexts" [10] and the latter as "any form of interactive computer-based game software for one or multiple players to be used on any platform and that has been developed with the intention to be more than entertainment" [11]. These two approaches can make otherwise "boring" activities more interesting and engaging to do, where users to a greater extent internalize behavior and become self-sufficient when performing a task they find interesting [12][13].

In this paper, we present and evaluate a serious game designed for helping people learn how to use energy more efficiently, and to support behavior change toward more sustainable energy habits [5]. Our contribution lies mainly in the design area, by demonstrating how to design an energyefficiency intervention that uses a theoretically grounded behavior change model[14]; a gamification framework for designing a serious game intervention[15]; a taxonomy for categorizing and understanding different player types [16]; a theory of motivation for assessing the potential for learning and understanding what type of motivation contributing to behavior change and engagement[12]; and finally showing how this can be evaluated quantitatively.

\section{BACKGROUND/THEORY}

A common problem for behavior change interventions is that they are "often based on simple, mostly unstated models of human behavior or, at best, are 'informed' by theory using methods that are tenuous and intuitive rather than systematic" [17]. When designing the Energy Piggy Bank, we based the design on a number of theories and frameworks in order to increase the possibility that it would have the desired effect. It is grounded in the COM-B model [14] (Capability, Opportunity, Motivation - Behavior) which a relatively recent but already well-established model for the conditions that need to be in place in order for an intervention to succeed. These conditions can be affected using a number of Behavior Change Techniques, where we have identified ten that we use. The tool

This research was funded by the Swedish Energy Agency. 
used for the intervention is the Energy Piggy Bank game which has been designed for the four Bartle Player Types, using Werbach's gamification framework, where an important aspect is to differ between extrinsic motivation and intrinsic motivation. We have therefore used the Intrinsic Motivation Inventory[18] to evaluate the intervention. These frameworks and theories are briefly described below.

\section{The COM-B model for behavior change}

According to the COM-B model [14] there are three contextual components to consider when attempting to change behavior. The person who is targeted must have both psychological and physical Capability to perform the behavior. (S)he must also have social and environmental Opportunity to perform the behavior; and finally, there must be sufficient Motivation to do the behavior, where motivation can be either automatic (habitual) or reflective (planned). For example, if the behavior is turning off the lights when leaving a room, the person performing the behavior need to:

- Know how an on/off switch works and have the physical skill to use it (Capability).

- Have access to an on/off switch and be in a social environment that allows for lights to be turned off (Opportunity).

- Be motivated to turn the lights off when leaving a room instead of not turning them off (Motivation).

\section{The Users in the Study}

Previous research suggest that effects of gamification and serious games interventions are greatly dependent on both the context in which the intervention is applied as well as the user targeted [19]. Looking at an energy efficiency context, Johnson et al [20] found that gamification and serious games appear to be of value, and evidence was found for a positive influence on behavior change, knowledge levels, learning, and improving user experience. Adding interactive elements have also been shown to have a positive effect on learning and engagement when learning about energy-related issues [21]. Previous work on user motivation suggest that different users interact with game-like systems in different ways and have different motivations [22], however, the extent to which effects of serious games interventions vary across user groups is still unclear [20].

One way to categorize users in a game context is by using the Bartle Player Type Taxonomy developed by Bartle [16]. The taxonomy proposes 4 player types, each with different propensities and motivations:

- Achievers - Regard points-gathering and rising in levels as their main goal.

- Explorers - Prefer to expose the game's internal machinations. The real fun comes only from discovery.

- Socializers - Like to connect with other people. The game is merely a backdrop, a common ground where things happen to players.
- Killers - Like to impose themselves on others. The more massive the distress caused, the greater the killer's joy at having caused it.

A common criticism of gamification is that gamification mechanisms such points, badges and leaderboards are extrinsically motivating mechanisms. The "players" can become focused on winning the game, or enter a "gamer mode" instead of focusing on the underlying goals [23]. In Werbach's gamification framework [15] it is therefore emphasized that more intrinsically motivating mechanisms should be used. How we have done this is described in the following section, and the result has been evaluated using the Intrinsic Motivation Inventory[18].

\section{Self-determination theory and intrinsic motivation}

Furthermore, according to the Self-determination theory, motivation can be either Intrinsic and Extrinsic [13]. Intrinsically motivated behaviors are those that are performed because they are found to be inherently interesting or valuable. Extrinsically motivated behaviors are those that are instrumental for achieving some goal separate to the activity itself. The theory further distinguishes between two types of extrinsic motivation. A behavior can be extrinsically motivated and performed with resistance and disinterest where the person performing the behavior "feels externally propelled into action" [12], or extrinsically motivated and performed with an attitude accepting the value of an activity and the extrinsic goal is "self-endorsed and adopted with a sense of volition" [12]. Using a (somewhat simplified) example, a person can turn off the lights when leaving a room because they find turning off the lights is inherently valuable, or they can turn off the lights because, if not, the landlord will increase rent, or they can turn off the lights knowing that energy conservation is an important part of achieving a sustainable future society, without necessarily finding the activity itself very interesting.

\section{The ENERgy Piggy BANK GAME}

The objective of the Energy Piggy Bank is to reduce household energy consumption by enabling and motivating the user to learn new energy habits (examples of the interface can be seen in figure 1). Framing the system using the COM-B model [14], its main focus is to increase psychological capability by making the user aware of simple actions that can be done at home to reduce energy consumption, and disrupting otherwise automatically motivated behaviors, as well as increasing reflective motivation where the participants become aware of, and tries to use, a number of energy saving actions. It uses a number of Behavior Change Techniques as defined in the Behavior Change Taxonomy [24]. These include:

2.1 Monitoring of behavior by others without feedback The participants are part of a team collectively collecting points by doing energy saving actions. The participants can see how many activities in each "room" each other participant performs daily, but in order to maintain integrity it is not possible to identify individual actions 
2.3 Self-monitoring of behavior - Each participant reports their own activities and observes their own behavior as long as the system is used.

2.7 Feedback on outcome of behavior - After marking an activity as completed, a supportive feedback message is given.

4.1 Instruction on how to perform a behavior - The system lists a number of behaviors that conserve energy, including one-time behaviors such as changing light bulbs and adjusting the temperature in the freezer.

5.1 Information about social and environmental consequences - For each behavior a factual text describing the consequences of the behavior in energy and/or environmental terms.

6.2 Social comparison - Each team member's contribution to the group's score is visualized using a pie chart, and the number of activities done by each group member is clearly visible in the group area.

7.1 Prompts/cues - Messages are sent at $8 \mathrm{pm}$ to the participants reminding them to $\log$ their activities. The reminders occur at a time when people are often at home and can perform a number of the activities as a result of the reminder.

8.3 Habit formation - One of the main techniques used, where the participant is encouraged to do the activities during a time period.

10.8 Incentive - The participants can see how many activities they need to perform in order to reach the next level ("level up") in the game.

10.10 Reward - The participants receives points and badges when performing the different activities.

The gamification of the Energy Piggy Bank was designed using Werbach's gamification framework [15] which involves six steps.

1. Define [business] objectives

2. Delineate target behaviors

3. Describe your players

4. Device activity cycles

5. Don't forget the fun!

6. Deploy the appropriate tools

Each step is described below.

\section{A. Define [business] objectives}

The main goal of the Energy Piggy Bank is to facilitate behavior change that enables a reduction in household energy consumption. It addresses a number of behavior change techniques, as described in the previous section.

\section{B. Delineate target behaviors}

There are two target behaviors. The first is that the
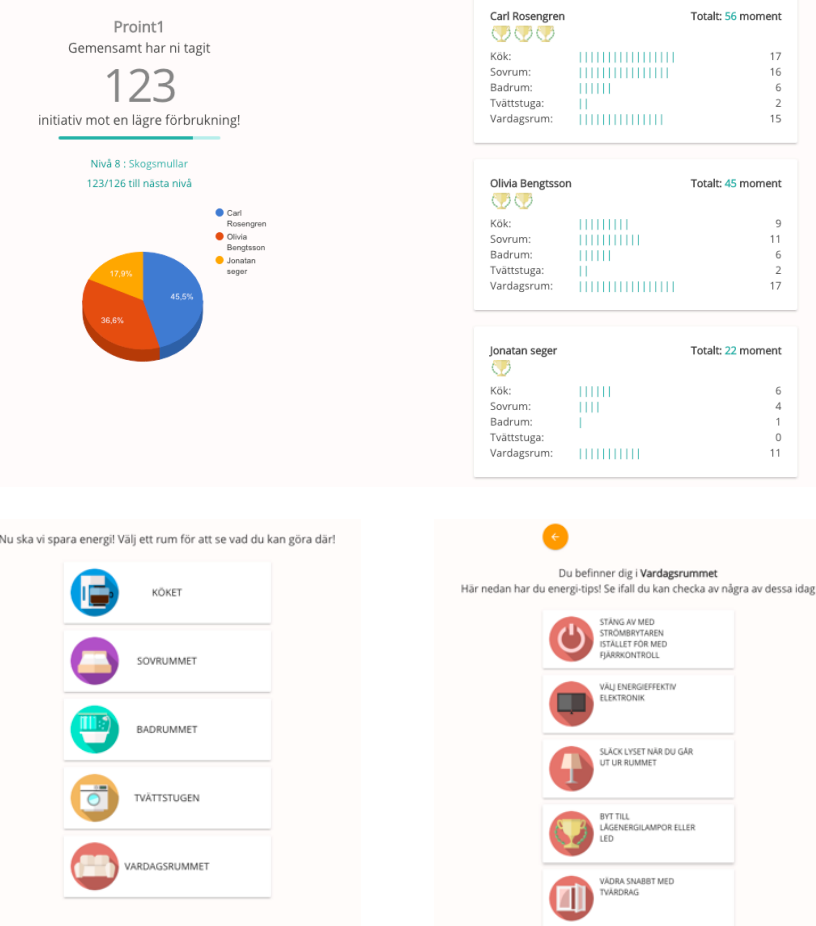

Fig. 1. Parts of the interface, showing group points, leaderboard and level (top left), individual points and badges (top right), the five different "rooms" where activities take place (lower left), possible activities in one of the rooms (lower right).

participants should do as many of the one-time energy saving activities as possible, each of which will have a long-term energy conserving function even after the "game" has ended. The metrics is very simple, the participant earns a badge. The second behavior is that the participants should try as many of the energy saving behaviors as possible, and if possible on a daily basis. The metrics for this is a bit more difficult. If a simple point mechanism was used where performing each action generated a point, it could be tempting for some to "game" the system by performing an activity several times in a row in order to score more points, even if the behavior is meaningless (for example boiling one liter of water by boiling one deciliter ten times instead of one liter one time). The mechanism is aimed at collaboration rather than competition, by earning points for your team rather than for yourself, which we hope will lead to players encouraging each other to perform energy saving actions. However, for competitive players who want to be "best" in the group the pie charts depicting each participant's contribution can be seen as a group leaderboard.

\section{Describe your players}

In general, the Energy Piggy Bank targets a very broad spectrum of participants. A player could be anyone with an interest in saving energy, or perhaps even a family member without any interest in saving energy but where one individual family member has that interest. In particular, groups with a common interest in saving energy and with plenty of opportunities to observe each other's behavior in real life, such as a family or a number of colleagues, are suited due to the collaborative aspects of the Energy Piggy Bank. Since we target already existing groups such as families, we designed the 
game to be appealing to all four of the Bartle Player Types, even though to a different extent. The achievers can become engaged by the badges and the points gathered while performing activities, and the group's and individual's progress together with the leveling system. The socializers can become engaged by the collective nature of the game, where you can observe your friend's progress. The explorers can become engaged by exploring all the suggestions for saving energy grouped in the five different "rooms", and seeing it as a challenge to complete the real-world activities associated with the suggestions. Finally, even though the game was not primarily designed for killers, they might become engaged the leaderboard-like system where you can outperform your friends in the group and could potentially even sabotage for your friends so they do not score points as much as they could (even if that is explicitly not the intended purpose).

\section{Device activity cycles}

The activity cycles evolve around daily reporting of energy saving activities performed during the day. The engagement loop motivates the participants differently for different player types, as described above.

The progression stair is very simple since we expect the player lifecycle to be relatively short. The Energy Piggy Bank does not add any new suggestions for energy saving, so when the group has played enough to reach the highest level we expect them to stop playing the game.

\section{E. Don't forget the fun!}

The Energy Piggy Bank was designed to be extremely easy to start with, using a kind of fun style. The name "Energy Piggy Bank" was chosen as a metaphor for how to save energy, and with the intention to associate saving energy with saving money, which is the major motivator for most people. When leveling up the team gets a new title, often with a rather silly pig-energy-related name (such as Energy Piglet).

\section{F. Deploy the appropriate tools}

The main gamification tools used are points, badges and leaderboards of a collective nature as described previously.

\section{METHODS}

\section{A. Procedure}

The participants in the study were 39 engineering students who as part of a course had to participate in one scientific study. This study was the first choice but with the possibility to decline and participate in another study instead. 21 were men and 18 were women and the age-span was 20-27 years old. One participant chose to decline due to other engagements during the time of the study, and five failed to complete the tasks leaving 33 students (18 men and 15 women) who completed the study as prescribed.

The participants first answered a questionnaire about how often they performed the various activities where energy saving suggestions were included in the Energy Piggy Bank (such as brew coffee, do laundry). They also answered which of the activities they did not have the possibility to do (such as fix leaking toilets if the toilet is not leaking). This gave us a baseline with which their reported activities during the trial could be compared.

Next, the participants were divided into 8 groups of about 4-6 participants per group. The participants were then given the instructions to, for three days Monday - Wednesday, log in to the system, check one dummy activity in order to make sure they actually had logged in, look at the group status and then voluntarily check the energy saving activities they had performed during the day. These activities as well as the group score were logged daily through the application database. The participants received a reminder at $8 \mathrm{pm}$ sent by email, the university's Learning Management System app and SMS (where 25 students had previously signed up to receive SMS notifications from the university), with a direct link to the Energy Piggy Bank system and a reminder of what was required. The next two days (Thursday - Friday) they were sent reminders as previously, but were no longer required to act on these reminders. Finally, for the last two days (Saturday Sunday) they were not sent any reminders but the previous instructions stated that if they wanted to they could continue to check off items on the list during the weekend.

\section{B. Questionnaires}

\section{Activity opportunity}

Before the trial period the participant filled out which of the activities in the Energy Piggy Bank game they had an opportunity to do. For example, one task in the application suggested that the user should "fix leaking toilet", which was only possible in the case that the user had a leaking toilet.

\section{Bartle test}

The participants completed the Bartle test consisting of 30 questions with each question containing two options answered according to which of the options the participant felt more inclined to do. Each participant then received a score on each of the player types (total of 200), for example "60" Achiever, "70" Explorer, "30" Socializer, and "40" Killer, in which case they would be categorized as an Explorer.

\section{Intrinsic Motivation Inventory}

Three constructs from the intrinsic motivation inventory [18] were measured to explore level of motivation and engagement. The constructs used were:

- Interest/enjoyment - Self-report measure of intrinsic motivation. Example question: "This activity was fun to do."

- Value/usefulness - Self report measure of potential for internalization of behavior. Example question: "I think this is important to do because it can help me learn how to save energy."

- Perceived Choice - Self report measure on the degree to which an activity is perceived as being subject to choice. Example Question: "I believe I had some choice about doing this activity.” 
Each item in the questionnaire was measured on a 7-point Likert scale from 1 (not true at all) to 7 (very true).

\section{Self-estimated Behavior Change}

After the trial period was over the participants filled out a questionnaire where they were asked to estimate future change in behavior. They were given a list of the activities that had appeared in the Energy Piggy Bank game and asked to estimate the extent to which they would perform the activity in the future. The scale was from 1 ("as before") to 5 ("always"), with the additional option "do not have the opportunity to perform the activity". The number of estimated changes was measured by counting all answers except "As Before" and "Do not have the opportunity".

\section{Activity performance}

Activity Performance was collected from database logs.

\section{RESULTS}

The results are presented as follows. First in Table.1 we present mean scores for the IMI-constructs Interest/enjoyment, Value/Usefulness and Perceived Choice organized under player type. In addition to the four player types we have have added the category "undefined" for participants that had, not one, but two top scores. For example, "Socializer 60, Achiever 60, Explorer 42, Killer 38" would be categorized as undefined.

In Table. 2 we present the correlation between player types and the three constructs Interest/enjoyment, Value/Usefulness and Perceived Choice. Table.2 also show the correlation between Self-estimated Behavior Change and the three constructs.

In Table.3 (available at http://bit.ly/2zt7Qd1 due to restricted number of pages) we present the result from the SelfEstimated Behavior Change

\section{A. Correlations}

We found a significant positive correlation between Selfestimated behavior change and Interest/enjoyment $(r=0,42, p$ $=0,016)$, Value/usefulness $(r=0,38, p=0,031)$, and Perceived choice $(r=0,42, p=0,015)$.

We found no significant correlation between player type and Interest/enjoyment, Value/usefulness, and Perceived choice, or player type and self-assessed levels of future behavior change. Achiever was the only player type with a positive correlation ( $\mathrm{r}$ $=0.27$ and $\mathrm{p}=0.13$ ) with Interest/Enjoyment the self-reported measure of motivation.

\section{B. Motivation/Engagement}

Interest/Enjoyment was highest for the player type Achiever $(4,02)$ and the Undefined group $(4,21)$, with a mean score of 3,6 across all player types including the undefined group. Value/Usefulness score was highest for the player type Explorer $(4,98)$, with a mean score of 4,50 across all players types including the undefined group. Perceived choice was highest for the player type Achiever $(2,78)$ with a mean score of 2,47 across all player types including the undefined group. The low score in perceived choice was expected since the participants had to participate in either this or some other similar activity as part of their course requirements.

\begin{tabular}{|c|c|c|c|}
\hline \multicolumn{4}{|c|}{ TABLE.2 Pearson's Correlation for dependent variables } \\
\hline & $\begin{array}{c}\text { Interest/ } \\
\text { Enjoyment }\end{array}$ & $\begin{array}{c}\text { Value/ } \\
\text { Usefulness }\end{array}$ & $\begin{array}{c}\text { Perceived } \\
\text { Choice }\end{array}$ \\
\hline SEBC & $0,42 *$ & $0,38^{*}$ & $0,42 *$ \\
\hline Killer & $-0,01$ & $-0,04$ & $-0,02$ \\
\hline Achiever & 0,27 & 0,11 & $-0,07$ \\
\hline Explorer & $-0,02$ & 0,06 & $-0,07$ \\
\hline Socializer & $-0,12$ & $-0,10$ & 0,16 \\
\hline * Significant at p < $0,05$. \\
SEBC = Self Estimated Behavior Change \\
\hline
\end{tabular}

\section{Self-Estimated Behavior Change.}

The Energy Piggy Bank included 28 activities that the participants could perform. For three $(11 \%)$ of the activities, more than $50 \%$ of the participants that had an opportunity to perform the activity estimated that they would do so more frequently after participating in the study (turn off lights when leaving room $58 \%$, disconnect chargers when not using $58 \%$, use a lid when boiling water $55 \%)$. For seven $(25 \%)$ of the activities, between $40 \%$ and $50 \%$ that had an opportunity to perform the activity estimated that they would do so more frequently after participating in the study. For eight $(28 \%)$ of the activities between $30 \%$ and $40 \%$ of the participants estimated they would perform them more frequently after the study, and for ten activities (36\%) below $30 \%$ of the participants estimated they would perform them more frequently after the study.

\section{DISCUSSION}

The Energy Piglet game was designed for all four Bartle player types and all participants independent of player type found the energy piglet intervention valuable in learning how to be more energy efficient at home.

Looking at what activities the participants thought they would keep doing in the future (self-estimated behavior change) those with the highest score were mainly those that are habitual and require on-going effort on part of the user. Arguably serious games interventions like the energy piglet can be effective in helping and incentivizing the user to learn and form new habits.

However, it is worth noting that although no significant correlations were found between player type and level of motivation and interest, Achiever was the only player type with a positive correlation $(\mathrm{r}=0.27$ and $\mathrm{p}=0.13)$ with Interest/Enjoyment (self-reported measure of motivation).

\begin{tabular}{|c|c|c|c|c|c|c|c|c|c|c|}
\hline \multicolumn{11}{|c|}{ TABLE.1 IMI-Questionnaire Result } \\
\hline & \multicolumn{2}{|c|}{ Killer $(\mathbf{N}=6)$} & \multicolumn{2}{|c|}{ Achiever (N=7) } & \multicolumn{2}{|c|}{ Explorer $(\mathrm{N}=8)$} & \multicolumn{2}{|c|}{ Socializer $(N=4)$} & \multicolumn{2}{|c|}{ Undefined $(\mathrm{N}=8)$} \\
\hline & Mean & $S D$ & Mean & $S D$ & Mean & $S D$ & Mean & $S D$ & Mean & $S D$ \\
\hline Value/Usefulness & 4,55 & 0,71 & 4,51 & 0,80 & 4,98 & 0,73 & 3,57 & 1,87 & 4,88 & 1,57 \\
\hline Perceived Choice & 2,05 & 0,97 & 2,78 & 0,87 & 2,38 & 0,70 & 2,43 & 1,06 & 2,70 & 1,28 \\
\hline
\end{tabular}


Although the game was designed with all player types in mind it does not seem implausible that the leaderboard and badges had more motivational salience and appeal to users categorized as Achievers despite being used in a social setting where the points scored contributed to the team.

We did see statistically significant correlation between intrinsic motivation (using the Intrinsic Motivation Inventory) and self-estimated future behavior change, pointing at that designers of serious games such as this should make sure that intrinsic motivation should be part of the game design.

It should finally be noted that the sample of 39 engineering students is not a representative sample, which might affect the generalizability of the results.

\section{CONCLUSION}

In this study, we looked at how a serious game can motivate people to learn energy efficient behaviors using:

- A model/framework/guide for understanding behavioral contextual factors, identifying barriers and choosing behavior change techniques.

- A taxonomy for categorizing the user (player types) and understanding how their different motivation and propensities.

- A gamification framework for designing a serious game intervention.

- A theory of motivation for assessing the potential for learning and understanding what type of motivation contributes to long-term behavior change and engagement.

Combining these theories and frameworks allowed us to design a serious game where the players were exposed to a number of energy saving suggestions, and where most players explored several of these suggestions. The game mechanisms built on exploration and collaboration which are factors that appeal to the player types Explorers and Socializers, but also had a point mechanism designed to appeal to Achievers. The game mechanism both encouraged one-time interventions which usually have the largest effect for energy conservation, and also encouraged starting building habits by encouraging repeated use of energy saving activities during the game.

We suggest that designers of serious games for energy conservation should consider all the theories and frameworks we used in this study. We further emphasize that in order for ICT-driven behavior change interventions to be successful it is important these interventions are mindful of the many barriers for achieving long-term behavior change, and aim at promoting behaviors that are intrinsically motivated which have a greater potential for standing the test of time. We hope that our approach can be used as inspiration and guide for other designers of serious games for sustainable development.

\section{REFERENCES}

[1] European Environment Agency, "Energy Efficiency and Energy Consumption in the Household Sector", Copenhagen, Denmark. EEA, 2012.
[2] W. Abrahamse, L. Steg, C. Vlek, and T. Rothengatter, "A review of intervention studies aimed at household energy conservation," Journal of environmental psychology, vol. 25, pp. 273-291, 2005.

[3] C. Gossart, "Rebound effects and ICT: a review of the literature," in ICT innovations for sustainability, ed: Springer, 2015, pp. 435-448.

[4] W. Abrahamse, L. Steg, C. Vlek, and T. Rothengatter, "The effect of tailored information, goal setting, and tailored feedback on household energy use, energy-related behaviors, and behavioral antecedents," Journal of environmental psychology, vol. 27, pp. 265-276, 2007.

[5] M. Z. Huber and L. M. Hilty, "Gamification and sustainable consumption: overcoming the limitations of persuasive technologies," in ICT Innovations for Sustainability, ed: Springer, 2015, pp. 367-385.

[6] B. J. Fogg, "Persuasive technology: using computers to change what we think and do," Ubiquity, vol. 2002, p. 5, 2002.

[7] J. Froehlich, L. Findlater, and J. Landay, "The design of eco-feedback technology," 2010, pp. 1999-2008.

[8] M. Swan, "The quantified self: Fundamental disruption in big data science and biological discovery," Big Data, vol. 1, pp. 85-99, 2013.

[9] B. Hedin and J. Zapico, "Kilowh. at-Increasing Energy Awareness Using an Interactive Energy Comparison Tool," 2017, pp. 175-185.

[10] S. Deterding, D. Dixon, R. Khaled, and L. Nacke, "From game design elements to gamefulness: defining gamification," 2011, pp. 9-15.

[11] P. Vorderer, U. Ritterfeld, R. L. Nabi, and M. B. Oliver, "Digital games," Sage handbook of media processes and effects, pp. 455-467, 2009.

[12] R. M. Ryan and E. L. Deci, "Self-determination theory and the facilitation of intrinsic motivation, social development, and well-being," American psychologist, vol. 55, p. 68, 2000.

[13] R. M. Ryan and E. L. Deci, "Intrinsic and extrinsic motivations: Classic definitions and new directions," Contemporary educational psychology, vol. 25, pp. 54-67, 2000.

[14] S. Michie, L. Atkins, and R. West, The behaviour change wheel : a guide to designing interventions. [UK]: Silverback, 2014.

[15] K. Werbach and D. Hunter, For the win: How game thinking can revolutionize your business: Wharton Digital Press, 2012.

[16] R. Bartle, "Hearts, clubs, diamonds, spades: Players who suit MUDs," Journal of MUD research, vol. 1, p. 19, 1996.

[17] S. Michie, D. Fixsen, J. M. Grimshaw, and M. P. Eccles, "Specifying and reporting complex behaviour change interventions: the need for a scientific method," Implement Sci, vol. 4, 2009.

[18] E. L. Deci and R. M. Ryan, "Intrinsic motivation inventory," SelfDetermination Theory, vol. 267, 2003.

[19] J. Hamari, J. Koivisto, and H. Sarsa, "Does gamification work?--a literature review of empirical studies on gamification," 2014, pp. 30253034.

[20] D. Johnson, E. Horton, R. Mulcahy, and M. Foth, "Gamification and serious games within the domain of domestic energy consumption: A systematic review," Renewable and Sustainable Energy Reviews, vol. 73, pp. 249-264, 2017.

[21] B. Hedin, J.L. Zapico: "Kilowh.at - Increasing Energy Awareness Using an Interactive Energy Comparison Tool". Proceedings from 12th International Conference, PERSUASIVE 2017, Amsterdam, The Netherlands, April 4--6, 2017, Proceedings. pp. 175-185. Springer International Publishing, Cham (2017).

[22] J. Hamari and J. Tuunanen, "Player types: A meta-synthesis," Transactions of the Digital Games Research Association, vol. 1, 2014.

[23] A. Frank, 'Gamer mode : Identifying and managing unwanted behaviour in military educational wargaming, $\mathrm{PhD}$ dissertation, Stockholm, 2014.

[24] A. Abraham and S. Michie. A taxonomy of behavior change techniques used in interventions. Health psychology, 27(3), 379, 2008 